\title{
A novel image hiding scheme by Optimal Pixel Pair Matching and Diamond Encoding
}

\author{
Rajashree Shitole ${ }^{1}$, Satish Todmal ${ }^{2}$ \\ ${ }^{1}$ (Department of Electronics \& Telecommunication Engineering, University of Pune, India) \\ ${ }^{2}$ (Department of Information Technology, Imperial College of Engineering \& Research, India)
}

\begin{abstract}
This paper describes a novel method of data embedding based on Pixel Pair Matching(PPM).In Optimal Pixel Adjustment Process (OPAP),pixel $x$ is embedded in k-bits of message $m$, using Least Significant Bit (LSB) substitution method by adjusting stego pixel at optimal level. In Diamond Encoding (DE), Diamond Characteristic Value, conceals secret digit in N-ary notational system when $k \geq 1$.Comparison and Experimental results of OPAP and DE not only demonstrates acceptable image quality but also provides significant improvements for different payloads. Diamond shape reveals that it is selective to specific notational system but large amount of data can be embedded in the cover image maintaining imperceptible stego-image quality.
\end{abstract}

Keywords - Diamond Encoding (DE), Exploiting Modification Direction (EMD), Least Significant Bit (LSB), Optimal Pixel Adjustment Process (OPAP), Pixel Pair Matching (PPM).

\section{Introduction}

Data hiding is a technique which imperceptibly embeds important data into media such as images, voice, documents, etc. Data Hiding is defined by T. Morkel as follows, "Steganography is art and science of invisible communication." Since, images are popular media on internet; they are majorly used as cover media for secret communication. The image which is used to hide the data is called cover image/ host image. Image in which data is hidden is called stego image and image which is to be concealed in the cover image is called as secret image. Acceptable data hiding provides large amount of data to be embedded in the cover image maintaining quality of stego image.

The most popular method of data hiding is Least Significant Bit method. There are basically two types of LSB methods LSB replacement and LSB matching. In both the cases data to be hidden is represented in binary form. Amount of data that can be embedded is called as embedding capacity and distortion present during embedding is called as embedding distortion. LSB method has average embedding capability. In this method each pixel of cover image is compared with data to be hidden depending upon even and odd values of pixels, they are increased or decreased respectively or kept unmodified. But because of this method, distortion during embedding increases, and results in degradable image quality. It becomes very easy to detect the change in values, because all these operations are performed on Least significant Bit [1][2] . In, 2001 Rang-Zan Wang et al. [3] proposed image data hiding scheme by optimal LSB substitution and genetic algorithm. But when this algorithm was implemented, Signal to Noise Ratio (SNR) obtained was much less than LSB substitution in some cases. Due to LSB replacement, embedding distortion increases, hence OPAP is conceptually defined as matching pixel to its optimal level was introduced. Basic concept of Pixel Pair Matching is to provide a new value of pixel pair with respect to value of reference pixel pair according to the secret message digit and new value of pixel pair is replaced by secret digit. In other words pixel pair is used for embedding, first pixel is used to carry one message bit and second pixel carries binary function related to it. In 2006, Mielikainen [4][5] proposed LSB matching method but here, two pixels were used to carry two bits. Therefore, error calculated is $(3 / 4) *\left(1^{2} / 2\right)=0.315$ of $1 \mathrm{bpp}$ [5]. Where as LSB error is 0.5. in the same year Xinpeng Zhang et al. proposed EMD. In this method, each secret digit present in $(2 n+1)$-ary notational system where $n=$ system parameter of cover pixels. Secret message is in binary form but when it is represented in decimal form or value, each secret digit is represented by $\mathrm{K}$, in a $(2 \mathrm{n}+1)$-ary notational system. In EMD, instead of payload image quality is enhanced.

The rest of this paper is organized as follows. Section II gives review of Exploiting Modification (EM) direction embedding skill. Section III will give framework of implemented method called Optimal Pixel Adjustment Process (OPAP). Section IV will present implementation of Diamond Encoding (DE). Quality analysis and comparison of OPAP and DE in terms of SNR is presented in Section V. Section VI includes Conclusions and Remarks. 


\section{Review Of The Exploiting Modification Direction Embedding Scheme}

The EMD method was proposed by Xinpeng Zhang et al. in 2006, which enhanced the image quality of stego image by fully exploiting the modification direction. The EMD method is described in [6][7]. The basic concept of EMD is $n$ cover pixels carry $(2 n+1)$-ary notational secret digit and only one pixel value is changed i.e. increased or decreased by 1 . In $n$ cover pixels, for one pixel $2 n$ states are possible pixel value 1 is added or subtracted. But if no pixels are modified $(2 n+1)$ different cases are obtained. Secret message (binary form) is segmented to $\mathrm{L}$ bits where $\mathrm{L}$ is given as

For eg.

$$
\mathrm{L}=\left[\mathrm{K} * \log _{2}(2 \mathrm{n}+1)\right]
$$

Secret message bits (1101 0110 1001) is segment as (23 11 14) in 5-ary rotational system where $\mathrm{L}=4$ and $\mathrm{K}=2$. Let $\mathrm{P}_{\mathrm{x} 1}, \mathrm{P}_{\mathrm{x} 2}, \ldots \mathrm{P}_{\mathrm{xn}}$ denote value of pixel in a group extraction function (f) is given as follows

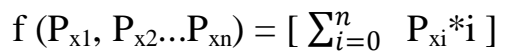

$$
\text { If } \mathrm{n}=2 \text {, }
$$

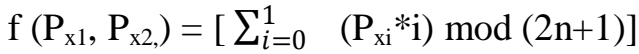

$$
\begin{aligned}
& =\left[\begin{array}{ll}
\sum_{i=0}^{1} & \left(\mathrm{P}_{\mathrm{xi}} *_{\mathrm{i}}\right) \bmod 5
\end{array}\right]
\end{aligned}
$$

In EMD payload cannot be increased and it is limited to 5-ary notational system. For extraction, more than one pixel needs to be modified, which affects overall performance. Hence OPAP is introduced.

\section{Optimal Pixel Adjustment Process (OPAP)}

This section describes the implemented technique based on PPM. Consider $\mathrm{P}_{\mathrm{xi}}, \mathrm{P}_{\mathrm{xi}} \square, \mathrm{P}_{\mathrm{xi}}{ }^{\prime \prime}$ represent pixel values at $i^{\text {th }}$ pixel in the host image $\mathrm{H}$, stego image is given as $\mathrm{S}$. Stego image $\mathrm{S}$ is calculated by LSB substitution method. It is basically represented in [8]. LSB substitution works as follows[4][5]

Let,

$$
\delta_{\mathrm{i}}=\mathrm{P}_{\mathrm{xi}} \square-\mathrm{P}_{\mathrm{xi}}
$$

where, $\delta_{\mathrm{i}}=$ embedding error

Cover or host image of $\mathrm{M}^{*} \mathrm{~N}$ pixels is represented as

$$
\mathrm{H}=\mathrm{x}_{\mathrm{ij}} \mathrm{E}\{0,1, \ldots 255\}
$$

Secret message $\mathrm{M}$ in $\mathrm{K}$ secret bit is

$$
\mathrm{m}=\left\{\mathrm{m}_{\mathrm{i}} \mid 0 \leq \mathrm{i}<\mathrm{n}, \mathrm{m}_{\mathrm{i}} \in\{0,1\}\right\}
$$

Secret message is rearranged to form a virtual message of $\mathrm{K}$-bit is denoted $\mathrm{m} \square$

where, $\mathrm{n} \square=\mathrm{M} * \mathrm{~N}$

$$
\mathrm{m} \square=\left\{\mathrm{m}_{\mathrm{i}} \square \mid 0 \leq \mathrm{i}<\mathrm{n} \square, \mathrm{m}_{\mathrm{i}} \square \mathrm{C}\left\{0,1 \ldots . .2^{\mathrm{k}-1}\right\}\right\}
$$

For embedding LSB substitution method is used

$$
\begin{aligned}
& \mathrm{m} \square=\left\{\mathrm{m}_{\mathrm{i}} \square\right\} \\
& \mathrm{m}_{\mathrm{i}} \square=\sum_{i=0}^{k-1} \mathrm{~m}_{\mathrm{i} * \mathrm{k}+\mathrm{j}} \square 2^{\mathrm{k}-1-\mathrm{j}}
\end{aligned}
$$

Therefore Stego image comprises of chosen pixel value $x_{l i}$ which stores K-bit of message $m_{i} \square$. Stego pixel is denoted by

$$
\mathrm{x}_{\mathrm{li}} \square=\mathrm{x}_{\mathrm{li}}-\mathrm{x}_{\mathrm{li}}{ }^{*} \bmod ^{*} 2^{\mathrm{k}}+\mathrm{m}_{\mathrm{i}} \square
$$

Therefore $P_{x i}$ is nothing but $x_{1 i} \square$. K is directly replaced by LSB of $P_{x i}$ with secret message bit.

$$
-2^{k}<\delta i<2^{k}
$$

Therefore to convert $\mathrm{P}_{\mathrm{xi}} \square$ to $\mathrm{P}_{\mathrm{xi}} \square \square$ i.e. original pixel to stego pixel three cases are defined.

Case 1: $\quad\left(2^{\mathrm{k}-1}<\delta \mathrm{i}<2^{\mathrm{k}}\right)$

$$
\begin{aligned}
& \mathrm{P}_{\mathrm{xi}} \square \square=\mathrm{P}_{\mathrm{xi}} \square-2^{\mathrm{k}} \quad ; \mathrm{P}_{\mathrm{xi}} \square \geq 2^{\mathrm{k}} \\
& =\mathrm{P}_{\mathrm{xi}} \square \quad \text {; otherwise }
\end{aligned}
$$


Case 2: $\left(-2^{\mathrm{k}-1} \leq \delta_{\mathrm{i}} \leq 2^{\mathrm{k}-1}\right)$

$$
\mathrm{P}_{\mathrm{xi}} \square \square=\mathrm{P}_{\mathrm{xi}} \square \quad \text {; for all }
$$

Case 3: $\quad\left(-2^{\mathrm{k}}<\delta_{\mathrm{i}}<-2^{\mathrm{k}-1}\right)$

$$
\begin{array}{rlrl}
\mathrm{P}_{\mathrm{xi}} \square \square=\mathrm{P}_{\mathrm{xi}} \square+2^{\mathrm{k}} & ; \mathrm{P}_{\mathrm{xi}} \square<256-2^{\mathrm{k}} \\
=\mathrm{P}_{\mathrm{xi}} \square & & ; \text { otherwise }
\end{array}
$$

So for optimal pixel pair matching, $\mathrm{P}=$ pixel value, $\mathrm{rLSB}=$ rightmost bit of $\mathrm{v}, \mathrm{P} \square=$ pixel value after embedding rLSB using LSB substitutions described above (8). Aim of OPAP is to adjust P; to its optimal level by decreasing embedding distortion.

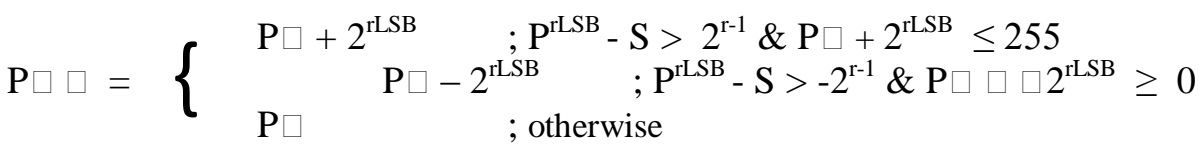

After embedding if value of $\mathrm{P}=160$ is changed to $\mathrm{P} \square \square=157$ according to the above stated conditions. It is proved that pixel pair is matched at optimum level. If last three bits of $\mathrm{P} \square \square$ are extracted, embedded data can be extracted very easily. But as value of $\mathrm{K}$ increases more than four, OPAP starts degrading the image quality.

\section{Diamond Encoding (De)}

The basic concept of DE is based on Pixel Pair Matching. It is an extension of EMD method described in section II[7]. DE is used to conceal the secret digit in $\mathrm{N}$-ary notational system into pixel pair where $\mathrm{N}=2 \mathrm{k}^{2}+$ $2 \mathrm{k}+1$ when $\mathrm{k} \geq 1$, where $\mathrm{k}$ is embedding parameter. Diamond Characteristic value is calculated so that one secret $\mathrm{N}$-ary digit is concealed.

Consider, size of cover image is $\mathrm{m} * \mathrm{~m}$ and secret message digit is $\mathrm{D}_{\mathrm{N}}, \mathrm{N}$ stands for $\mathrm{N}$-ary notational system. But embedding parameter $\mathrm{k}$ should satisfy the following condition:

$$
\left[\frac{m * m}{2}\right] \geq\left|\mathrm{S}_{\mathrm{N}}\right|
$$

Where, $\left|\mathrm{S}_{\mathrm{N}}\right|$ represents no. of secret message digits in $\mathrm{N}$-ary notational system. Let a, b, $\mathrm{x}$ and y be pixel values, the new set of pixel value which is to be found is called neighbourhood set denoted by $S_{k}(x, y),(a, b)$ is set of coordinates whose distance $(\mathrm{x}, \mathrm{y})$ is less than or equal to $\mathrm{k}$.

$$
\mathrm{S}_{\mathrm{k}}(\mathrm{x}, \mathrm{y})=\{(\mathrm{a}, \mathrm{b})|| \mathrm{a}-\mathrm{x}|+| \mathrm{b}-\mathrm{y} \mid \leq \mathrm{k}\}
$$

$\left|S_{k}\right|$ gives us value of embedded base with parameter $k$. Value of $\left|S_{k}\right|$ is defined by embedding parameter $k$, when $\mathrm{k}=1,2,3 \ldots . \mathrm{N} ; \mathrm{S}_{\mathrm{k}}$ obtained will be $\left|\mathrm{S}_{1}\right|=5,\left|\mathrm{~S}_{2}\right|=13,\left|\mathrm{~S}_{3}\right|=25 \ldots$ and so on respectively.

$$
\begin{aligned}
\left|\mathrm{S}_{\mathrm{k}}\right| & =\left[\left(\sum_{i=0}^{k}(2 i+1)\right)+\left(\sum_{i=1}^{k} 2 i-1\right)\right] \\
& =1+\left[\left(\sum_{i=1}^{k}(2 i+1)\right)+\left(\sum_{i=1}^{k} 2 i-1\right)\right] \\
& =1+\left[\sum_{i=1}^{k}(4 i)\right] \\
& =1+\frac{k(k+1)}{2} * 4 \\
& =1+2 \mathrm{k}(\mathrm{k}+1) \\
& =2 \mathrm{k}^{2}+2 \mathrm{k}+1
\end{aligned}
$$

Now, DCV is calculated for embedding and extracting process by using diamond function f. DCV is calculated as follows

$$
f(x, y)=((2 k+1) * x+y) \bmod N
$$


when $\mathrm{f}(\mathrm{x} \square, \mathrm{y} \square)=\mathrm{S}_{\mathrm{B}}$ then (x, y) is replaced by under flowing or overflowing, (x $\left.\square, \mathrm{y} \square\right)$ must be adjusted finely. Thus, four conditions of adjustments are as follows

1. If $\mathrm{x} \square>255, \mathrm{x} \square=\mathrm{x} \square-\mathrm{N}$

2. If $\mathrm{x} \square<0, \mathrm{x} \square=\mathrm{x} \square+\mathrm{N}$

3. If $\mathrm{y} \square>255, \mathrm{y} \square=\mathrm{y} \square-\mathrm{N}$

4. If $\mathrm{y} \square<0, \mathrm{y} \square=\mathrm{y} \square+\mathrm{N}$

In the diamond encoding method, when neighbourhood values are found, they form a diamond shape. Payload is given by $1 / 2 \log _{2}\left(2 k^{2}+2 k+1\right)$ bpp. So, it is proved that, pixel vector $(x, y)$ does not go beyond the value embedding parameter $\mathrm{k}$ even after embedding is completed. It is concluded that maximum data can be embedded in the cover image without degrading the quality of the stego image.

\section{Quality Analysis and Comparison}

Whenever any Stego image is created, some new data is embedded in the original/ cover or so called Host image. Because of this embedding, pixel values are modified. To measure the quality of stego image SNR, MSE, etc. are used. So, here, we are dealing SNR of OPAP and DE. SNR is defined as the ratio of signal to noise between cover and stego image. Larger value of SNR denotes better stego image quality. Mathematically, SNR is defined as follows

Where,

$$
S N R=\frac{\left.\sum_{x=0}^{m-1} \sum_{y=0}^{n-1} f 1(x, y)\right] 2}{\sum_{x=0}^{m-1} \sum_{y=0}^{n-1}[f 1(x, y)-f(x, y)] 2}
$$

$$
\begin{aligned}
& f(x, y)=\frac{\text { Original Image }}{\text { Cover Image or Host Image }} \\
& f_{1}(x, y)=\frac{\text { Stego Image }}{\text { Secret or Embedded Image }}
\end{aligned}
$$

SNR value in $\mathrm{dB}$ given by,

$$
\mathrm{SNR}_{\mathrm{dB}}=10 \log _{10} \mathrm{SNR}
$$

\section{Analysis of SNR}

\subsection{LSB Substitution[8]}

When bit is embedded in $\mathrm{i}^{\text {th }} \mathrm{LSB}$, SNR is given as:

$$
\mathrm{SNR}_{\mathrm{LSB}}=\frac{6}{(4 \mathrm{r}-1)}
$$

\subsection{Optimal Pixel Adjustment Process [3]}

The probability of $\mid \mathrm{P}-\mathrm{P} \square \square$ lies in the range of $\left[1,2^{\mathrm{rLSB}}-1\right]$ is $1 / 2^{\mathrm{rLSB}}$

$$
\mathrm{SNR}_{\mathrm{OPAP}}=\frac{12}{(4 \mathrm{rLSB}+2)}
$$

\subsection{Diamond Encoding [7]}

Digits are embedded in $\mathrm{N}$-ary notional system :

Where,

$$
\begin{aligned}
\mathrm{SNR}_{\mathrm{DE}}= & \frac{12}{\frac{1}{2 \mathrm{~N}} \sum_{y=0}^{k} \sum_{x=y-k}^{k-y}(\mathrm{x} 2+\mathrm{y} 2)+\sum_{y=1}^{k} \sum_{x=y-k}^{k-y}(\mathrm{x} 2+\mathrm{y} 2)} \\
& =\frac{k(k+1)\left(k^{2}+k+1\right)}{3+6 k(k+1)}
\end{aligned}
$$

$\mathrm{x}, \mathrm{y}=\mathrm{New}$ pixel pair which uses diamond shape,

$\mathrm{x}_{\mathrm{i}}$ and $\mathrm{y}_{\mathrm{i}}$ is reference co-ordinates,

$\mathrm{k}=$ Embedding parameter 


\begin{tabular}{|c|c|c|c|c|c|}
\hline $\begin{array}{c}\text { Sr. } \\
\text { No. }\end{array}$ & $\begin{array}{c}\text { Cover } \\
\text { image }\end{array}$ & $\begin{array}{c}\text { Size of cover } \\
\text { image } \\
\text { (bits) }\end{array}$ & Secret image & $\begin{array}{c}\text { Size of secret image } \\
\text { (bits) }\end{array}$ & $\begin{array}{c}\text { SNR with } \\
\text { OPAP } \\
(\mathbf{d b})\end{array}$ \\
\hline 1. & Baboon & $500 \times 500$ & Lena & $250 \times 250$ & 35.406 \\
\hline 2. & Kelly & $500 \times 500$ & Lena & $250 \times 250$ & 33.833 \\
\hline 3. & Baboon & $500 \times 500$ & Pepper & $250 \times 250$ & 35.370 \\
\hline 4. & Kelly & $500 \times 500$ & Pepper & $250 \times 250$ & 33.917 \\
\hline
\end{tabular}

Table no.2 SNR of DE

\begin{tabular}{|c|c|c|c|c|c|}
\hline $\begin{array}{l}\text { Sr. } \\
\text { No. }\end{array}$ & $\begin{array}{c}\text { Cover } \\
\text { image }\end{array}$ & $\begin{array}{c}\text { Size of cover image } \\
\text { (bits) }\end{array}$ & Secret image & $\begin{array}{c}\text { Size of secret image } \\
\text { (bits) }\end{array}$ & $\begin{array}{c}\text { SNR with } \\
\text { DE } \\
(\mathbf{d b})\end{array}$ \\
\hline 1. & Baboon & $500 \times 500$ & Lena & $250 \times 250$ & 39.479 \\
\hline 2. & Kelly & $500 \times 500$ & Lena & $250 \times 250$ & 38.003 \\
\hline 3. & Baboon & $500 \times 500$ & Pepper & $250 \times 250$ & 39.485 \\
\hline 4. & Kelly & $500 \times 500$ & Pepper & $250 \times 250$ & 37.992 \\
\hline
\end{tabular}

It is clear from TABLE 1 and 2, large amount of data is embedded in cover image without losing imperceptibility of the image. When the size of cover image and secret image is same, SNR is decreased. But when secret image is less than cover image, the average value of SNR for DE according to readings in TABLE 2 is 38.739 whereas for OPAP is 34.631.Therefore we obtain acceptable image quality compared to LSB substitution and EMD. It is also proved that number of bits which can be changed in OPAP is maximum 3 and for DE it is 8.Therefore large amount of data is embedded in DE compared to OPAP and EMD.

Table no. 3 SNR Comparison of DE with OPAP

\begin{tabular}{|c|c|c|c|c|c|}
\hline $\begin{array}{c}\text { Sr. } \\
\text { No. }\end{array}$ & $\begin{array}{c}\text { Cover } \\
\text { image }\end{array}$ & Secret image & $\begin{array}{c}\text { SNR with } \\
\text { OPAP } \\
(\mathbf{d b})\end{array}$ & $\begin{array}{c}\text { SNR with DE } \\
(\mathbf{d b})\end{array}$ & $\begin{array}{c}\text { SNR improvement } \\
\text { of DE over OPAP } \\
(\mathbf{d b})\end{array}$ \\
\hline 1. & Baboon & Lena & 35.406 & 39.479 & 4.073 \\
\hline 2. & Kelly & Lena & 33.833 & 38.003 & 4.170 \\
\hline 3. & Baboon & Pepper & 35.370 & 39.485 & 4.115 \\
\hline 4. & Kelly & Pepper & 33.917 & 37.992 & 4.075 \\
\hline
\end{tabular}

TABLE 3, indicates SNR comparison of OPAP and DE and SNR improvement of DE over OPAP. From this comparison it is clear that DE outperforms EMD and OPAP outperforms LSB substitution in terms of embedding efficiency, quality of stego image, etc. Fig. 1and Fig. 2 show the cover image Baboon and secret image of Lena and Pepper using OPAP and DE respectively. 


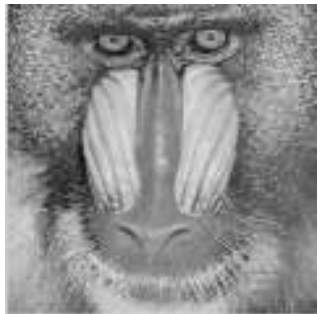

i]

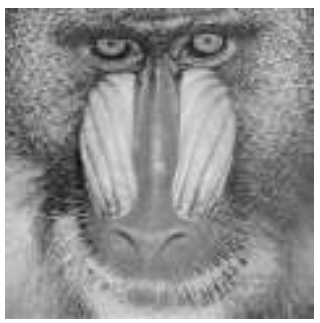

i]

Fig. 1. i] Cover image

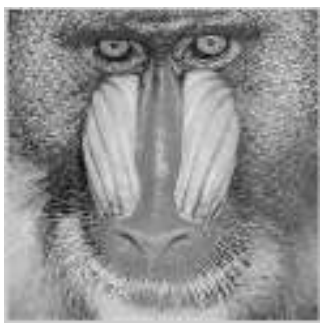

i]

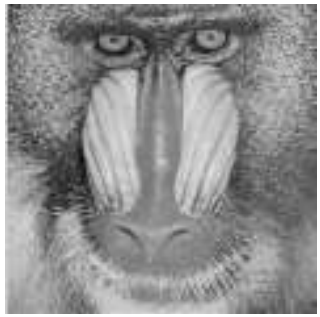

i]

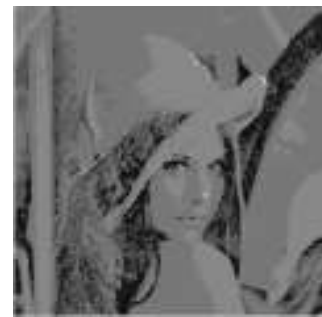

ii]

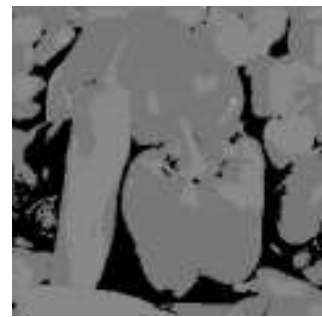

ii]

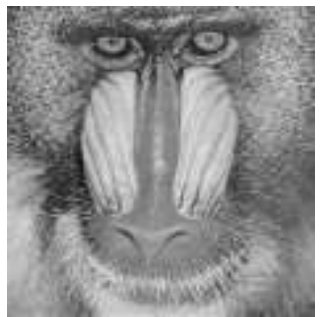

iii]

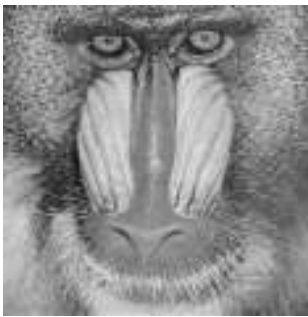

iii]

ii] Secret image and iii] Stego image by OPAP

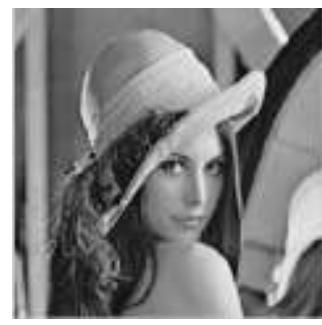

ii]

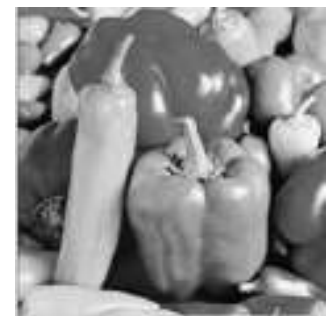

ii]

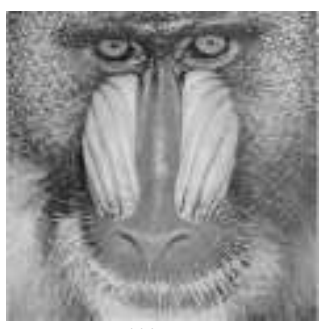

iii]

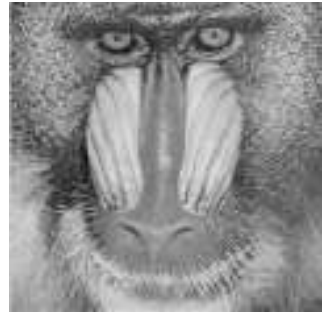

iii]

Fig. 2. i] Cover image ii] Secret image and iii] Stego image by DE

From Fig. $1 \& 2$ it is proved that DE gives better result compared to OPAP in terms of image quality.

\section{Conclusion}

This paper implements two efficient data embedding techniques. Optimal Pixel Adjustment Process gives acceptable image quality as compared to Least Significant Bit substitution method whereas Diamond Encoding enhances SNR.SNR improvement shown in TABLE 3 concludes DE outperforms OPAP as pixel improvement is of minimum $4 \mathrm{db}$. When an image having large areas with same color shades are used as cover image, change in pixel can be easily detected in OPAP. Clearly, the embedding parameter $k$ which is derived by $\mathrm{N}$-ary notational system in DE allows bit replacement up to 8 bits which is limited in OPAP. DE gives no artifacts in stego image for specific value of $\mathrm{k}$, and large amount of data can be embedded in cover image maintaining stego image quality or imperceptibility of an image. DE gives comparatively a better performance with respect to EMD, LSB substitution and OPAP. However with increasing values of $k$, pixel pair matching in an adaptive manner can be considered as an alternate approach. 


\section{References}

[1] J. Fridrich, M. Golijan, and R. Du, "Reliable detection of LSB steganography in color and grayscale images," in Proc. Int. Workshop on Multimedia and Security, 2001, pp. 27-30

[2] A. D. Ker, "Steganalysis of LSB matching in grayscale images” IEEE Signal Process. Lett. vol. 12, no. 6, pp. 441-444, Jun. 2005

[3] Ran-Zan Wang, Chi-Fang Lin, Ja-Chen Lin, "Image hiding by optimal LSB substitution and genetic algorithm," Pattern Recognition, vol.34, no. $3,671683,2001$

[4] C. H. Yang, "Inverted pattern approach to improve image quality of information hiding by LSB substitution," PatternRecognit. vol. 41, no.8, pp. 2674-2683, 2008

[5] J. Mielikainen, “LSB Matching revisited,” IEEE Signal Process. Lett. vol.13, no. 5, pp. 285-287, May 2006.

[6] J. Wang, Y Sun, H. Xu, K. Chen, H. J. Kim, and S. H. Joo, "An improved section wise exploiting modification direction method," Signal Process., vol. 90, no. 11, pp. 2954-2964, 2010.

[7] Xinpeng Zhang and Shuozhong Wang, "Efficient Steganographic embedding by exploiting modification direction," IEEE Communication Lett. Vol. 10, no.11, Nov. 2006

[8] Chi- Kwong Chan, L.M. Cheng, "Improved hiding data in images in optimal moderately significant bit replacement," IEE electron. Lett. 37, vol. 16, pp. 1017-1018, 2001 